Article

\title{
Thermoplastic Elastomeric Composites Filled with Lignocellulose Bioadditives, Part 2: Flammability, Thermo-Oxidative Aging Resistance, Mechanical and Barrier Properties
}

\author{
Justyna Miedzianowska *, Marcin Masłowski@ and Krzysztof Strzelec \\ Institute of Polymer \& Dye Technology, Lodz University of Technology, Stefanowskiego 12/16, 90-924 Lodz, \\ Poland; marcin.maslowski@p.lodz.pl (M.M.); krzysztof.strzelec@p.lodz.pl (K.S.) \\ * Correspondence: justyna.miedzianowska@dokt.p.lodz.pl; Tel./Fax: +48(42)-636-2543
}

Received: 2 March 2020; Accepted: 30 March 2020; Published: 1 April 2020

check for updates

\begin{abstract}
The work covers the characteristics of the functional properties of composites bordering thermoplastics and elastomers. The research is a continuation of considerations on blends in the form of a mixture of natural rubber (NR) with an ethylene-vinyl acetate copolymer (EVA) and the addition of a lignocellulose biofiller (wheat straw). After describing the processing and rheology as well as examining the thermal properties and morphology of composites (Part 1), the second part focuses on the characteristics of their performance. The effect of both different ratios of mixed polymers and the amount of filler on tensile strength and elongation at break, resistance to thermo-oxidative aging, hardness, tear resistance, barrier and damping properties, as well as flammability were investigated. The increased EVA content has shown a positive effect on tensile strength, elongation at break, resistance to thermo-oxidative aging, hardness, relative damping, tear strength, barrier and burning delay. On the other hand, a larger amount of natural rubber provides high flexibility and promotes the creation of a reinforcing structure by the filler used. Moreover, a significant impact of the addition of cereal straw on the barrier, damping, strength and flammability properties of composites was also noted. The great advantage of the prepared compositions in relation to commercial plastics is their environmental friendliness, primarily by replacing some petroleum derivatives of plastics with natural rubber and straw fibers.
\end{abstract}

Keywords: thermoplastic elastomer blends; straw; waste management; mechanical and barrier properties; aging resistance; flammability

\section{Introduction}

Thermoplastic elastomers (TPEs) constantly arouse the great interest of scientists, hence they are the subject of many studies and considerations described in the literature [1,2]. The goal of this research is always to obtain a material with the desired application properties, i.e., adapting an appropriate response to the growing needs and expectations of the industry. The field of TPEs involves all those products that must be able to return to their original shape after stress removal, but also to be able to be recycled [3]. TPEs are prepared by physical melt mixing of a polyolefin with an elastomer gained considerable attention because their macroscopic mechanical properties (impact strength, elongation at break) can be modified over a wide range by controlling the mixture composition [4-6]. Usually, blend ingredients are selected to complement both their pros and cons. For example, the main disadvantage of natural rubber is low aging resistance, and the EVA copolymer is characterized by high resistance. On the other hand, the flexibility of EVA itself may be too small for some applications, and the addition of NR significantly increases it. 
The widespread use of polymers in the packaging, automotive, household appliances, electrotechnical and many other industries has led to several important problems. The biggest of them include growing pollution of the natural environment, depletion of raw materials for polymer synthesis and rising oil prices. Biocomposites, more environmentally friendly composites than traditional materials, can solve these problems [7-9]. In the case of biocomposites based on a synthetic polymer, fillers play the role of a natural component. An example is the starch [10], characterized by a low price, and the cellulose as a potential substitute for petrochemical polymers [11].

Fiber biofillers are becoming an increasingly frequent topic of research. The use of a filler in the fibrous form allows to additionally control the properties of composites in a wide range, depending on the selection and orientation of the fibers used [12,13]. Natural fibers have aroused great interest as a new type of thermoplastic elastomer filler because they increase strength and dissipate accumulated energy. At the same time, they are renewable, cheap, less destructive to processing systems and easy to modify chemically and physically $[14,15]$. In addition, natural fibrous materials have many advantages over glass or carbon fibers: low density, lower machine wear, high flexibility, non-toxicity, biodegradability, rigidity, availability from natural sources, renewable energy, efficiency and low cost [16-18]. Problems with the management of used plastics and the limited resources of substrates for their production meant that countless scientists are trying to replace them, at least in part, with materials of natural origin, creating, for example, biocomposites. Although natural fibers are one of the fastest growing polymer additives, the use of straw as a filler is still a relatively new and scientifically attractive idea [19-22].

The aim of the presented work was to obtain new biocomposites, materials of which properties are more favorable to nature and human activity than traditional materials. A composite consisting of a synthetic polymer and a natural filler is, therefore, an interesting solution in ecological and economic terms. The use of straw as a filler is also a potential solution to the problem of its management. The methods employed so far to use excess straw have some disadvantages and adding it to polymers and obtaining products with nondeteriorated and even better properties may be an interesting goal. When used in a traditional elastomer, however, the problem may be the high processing temperature required by the crosslinking process, which can lead to straw fiber degradation. The answer to this issue may be polymer mixtures which can be prepared at much lower temperatures than those for vulcanizates obtaining. The aspect was confirmed in the first part of this work on morphology, processing, thermal and rheological properties of such systems.

Based on previous studies, it has been confirmed that the application of the proposed technological and material solution causes significant benefits: no chemical crosslinking, reduction of processing temperature, prevention of fiber degradation, energy and economic savings. The present study, as a continuation of previous investigations, aimed to outline a set of new properties of the new biocomposites obtained and reported in the first part of this work. Thus, the biocomposites made of natural rubber (NR), ethylene-vinyl acetate (EVA) copolymer and lignocellulose biofiller (cereal straw) were found to exhibit improved performances by considering their mechanical characteristics, resistance to thermo-oxidative aging, flammability barrier and dumping properties.

\section{Materials and Methods}

\subsection{Materials}

- Polymer

Natural rubber (NR) RSS I was provided by Torimex-Chemicals (Lodz, Poland). Natural, polymeric product was obtained from rubber milk secreted by Hevea brasiliensis tress, with a density of $0.930-0.988 \mathrm{~g} / \mathrm{cm}^{3}$ at $20^{\circ} \mathrm{C}$ and a decomposition temperature below $200{ }^{\circ} \mathrm{C}$ (data based on safety data sheet).

Ethylene-vinyl acetate copolymer (EVA) known as EVA $1020 \mathrm{VN} 5$ with a vinyl acetate content of $17.5 \%$, a melt flow index of $2 \mathrm{~g} / 10 \mathrm{~min}\left(190{ }^{\circ} \mathrm{C}, 2.160 \mathrm{~kg}\right)$ and density of $0.94 \mathrm{~g} / \mathrm{cm}^{3}$ was supplied by Total Petrochemicals (Houston, TX, USA). 
- Fillers

Cereal (wheat, oat, rye, barley and triticale) straw was collected from Polish farms. Straw was dried and next crushed using a Blixer 4 Robot Coupe (Vincennes, France)—grinding time of $20 \mathrm{~min}$. Then sieve analysis was performed by using: vibratory shaker, set of sieves with 2.0, 1.0, 0.5, $0.25 \mathrm{~mm}$ nominal mesh size. In the following studies, the fractions $0.5-0.25$ and $>0.25 \mathrm{~mm}$ were ground using a Fritsch Pulverisette 5 Classic Line planetary ball mill (Idar-Oberstein, Germany) for $2 \mathrm{~h}$, a speed of $3000 \mathrm{rpm}$ and a break of $30 \mathrm{~min}$ after $1 \mathrm{~h}$. The compositions of NR/EVA and NR/EVA/straw are presented in Table 1. Each of the polymer mixtures was prepared in quantities such NR and EVA constituted 100 parts per hundred rubber.

Table 1. The composition of polymer mixtures.

\begin{tabular}{|c|c|c|c|}
\hline \multirow{2}{*}{ Sample Name } & Natural Rubber & Ethylene-Vinyl Acetate & Straw \\
\hline & \multicolumn{3}{|c|}{ [phr] } \\
\hline $70 / 30$ & \multirow{4}{*}{70} & \multirow{4}{*}{30} & 0 \\
\hline $70 / 30 / 10$ & & & 10 \\
\hline $70 / 30 / 20$ & & & 20 \\
\hline $70 / 30 / 30$ & & & 30 \\
\hline $60 / 40$ & \multirow{4}{*}{60} & \multirow{4}{*}{40} & 0 \\
\hline $60 / 40 / 10$ & & & 10 \\
\hline $60 / 40 / 20$ & & & 20 \\
\hline $60 / 40 / 30$ & & & 30 \\
\hline $50 / 50$ & \multirow{4}{*}{50} & \multirow{4}{*}{50} & 0 \\
\hline $50 / 50 / 10$ & & & 10 \\
\hline $50 / 50 / 20$ & & & 20 \\
\hline $50 / 50 / 30$ & & & 30 \\
\hline $40 / 60$ & \multirow{4}{*}{40} & \multirow{4}{*}{60} & 0 \\
\hline $40 / 60 / 10$ & & & 10 \\
\hline $40 / 60 / 20$ & & & 20 \\
\hline $40 / 60 / 30$ & & & 30 \\
\hline $30 / 70$ & \multirow{4}{*}{30} & \multirow{4}{*}{70} & 0 \\
\hline $30 / 70 / 10$ & & & 10 \\
\hline $30 / 70 / 20$ & & & 20 \\
\hline $30 / 70 / 30$ & & & 30 \\
\hline
\end{tabular}

Phr-Parts Per Hundred Rubber.

\subsection{Methods}

Elastomer mixtures, based on natural rubber/ethylene-vinyl acetate copolymer and straw (Table 1), were prepared using an internal mixer (Brabender, Germany) at $80^{\circ} \mathrm{C}$ with $50 \mathrm{rpm}$.

The polymer mixtures were formed using steel molds placed between the shelves of an electrically heated hydraulic press. The samples were pressed at $100^{\circ} \mathrm{C}$, at $15 \mathrm{MPa}$ pressure for $10 \mathrm{~min}$.

Mechanical properties of composites were measured by using a universal machine (Zwick, Ulm, Germany) in accordance with standard International Organization for Standardization (ISO) 37 by using standard dumbbell-shaped samples. The samples were subjected to a stress-strain test at a cross-head speed of $500 \mathrm{~mm} / \mathrm{min}$. The measurements were performed at room temperature. From the obtained stress-strain curve, tensile strength (TS) and elongation at break (Eb) were determined. The obtained results from the 5 specimens for each composite were averaged.

The thermo-oxidative aging characteristics were determined according to the PN-82/C-04216 standard. Samples were exposed to air at an elevated temperature $\left(70{ }^{\circ} \mathrm{C}\right)$ for 14 days in a dryer FD (Binder, Tuttlingen, Germany) with thermo-circulation. To estimate the resistance of the blends to aging, their mechanical properties after aging were determined and compared with the values obtained 
for the blends before the aging process. The aging factor $(\mathrm{K})$ was calculated as the numerical change in the mechanical properties of the samples upon aging (Equation (1)) [23]:

$$
\mathrm{K}=\left(\mathrm{TS} \cdot \mathrm{E}_{\mathrm{b}}\right)_{\text {after aging }} /\left(\mathrm{TS} \cdot \mathrm{E}_{\mathrm{b}}\right)_{\text {before aging }}
$$

The hardness of blends was determined according to ISO 868 standard using a Shore type A Durometer (Zwick, Ulm, Germany) and the results were averaged considering ten points randomly chosen for each sample.

Tear strength tests were carried out by a universal testing machine (Zwick, Ulm, Germany) in accordance with ISO 34 standard (dimensions of samples-100 $\mathrm{mm} \times 15 \mathrm{~mm}$, trouser pieces, test speed-50 $\mathrm{mm} / \mathrm{min}$ ). Measurements were repeated five times.

The relative damping of composites was measured according to the PN-C-04289 standard by using the disc-shaped samples, with the following dimensions: diameter $-35 \mathrm{~mm}$ and height $-17.5 \mathrm{~mm}$. The analysis was carried out at room temperature by using a universal machine (Zwick, Ulm, Germany). Each sample was stressed from 0 to $0.7 \mathrm{MPa}$ and then stress was gradually reduced. The loading-unloading cycle was repeated five times. Hysteresis loops were recorded and the relative damping values were determined according to the Equation (2) [24].

$$
\mathrm{T}_{\tau \mathrm{w}}=\frac{\Delta \mathrm{W}_{\mathrm{i}}}{\mathrm{W}_{\mathrm{ibel}}} \cdot 100
$$

where: $T_{\tau \mathrm{w}}$ is the relative damping (in \%), $\Delta \mathrm{W}_{\mathrm{i}}$-the difference between the compression work and the work during reducing the compressive stresses and $\mathrm{W}_{\text {ibel }}$-compression work.

The flammability of blends was performed by, measuring the combustion time of samples $(50 \times$ $10 \times 4 \mathrm{~mm}$ ) in the air. The sample tip was ignited for $5 \mathrm{~s}$ by means of a gas burner supplied with propane-butane mixture.

Barrier properties were evaluated based on the through-plane air permeability of composites using the manometric method in accordance with the American Society for Testing and Materials (ASTM) D1434 standard. The tests were conducted by using atmospheric air at room temperature. Measurement of the barrier properties was based on a pressure difference between the chambers on both sides of the sample.

The barrier properties were expressed by gas transmission rate (GTR) and coefficient of gas permeability (P), according to the Equations (3) and (4) [25]:

$$
\begin{aligned}
\text { GTR } & =\frac{V_{c}}{R \cdot T \cdot P_{u} \cdot A} \cdot \frac{d p}{d t} \\
P & =\text { GTR } \cdot d
\end{aligned}
$$

where $\mathrm{d}$ is the thickness of the sample $[\mathrm{m}], \mathrm{V}_{\mathrm{c}}$-volume of low-pressure chamber [L], T-temperature $[\mathrm{K}], \mathrm{P}_{\mathrm{u}}-$ gas pressure in the high-pressure chamber $[\mathrm{Pa}], \mathrm{A}-$ permeation area of gas through the sample $\left[\mathrm{m}^{2}\right], \mathrm{dp} / \mathrm{dt}$ - pressure changes per unit time $[\mathrm{Pa} / \mathrm{s}], \mathrm{R}$-gas constant $8.31 \cdot \times 10^{3}(\mathrm{~L} \cdot \mathrm{Pa}) /(\mathrm{K} \cdot \mathrm{mol})$.

In the case of mechanical properties, i.e., tensile strength, tear strength, hardness, damping properties and flammability, a statistical analysis based on standard deviation was applied.

\section{Results and Discussion}

\subsection{Mechanical Properties}

The results of mechanical properties for the tested composites are presented in Table 2. In the case of unfilled blends, the tensile strength increased with increasing EVA content in the composite. The reason for the low mechanical strength at high relative elongation is the low degree of physical crosslinking due to the EVA phase in glassy-crystalline state at room temperature. Thus, the TS value of the NR/EVA 70/30 composite was only 3.5 MPa, and the composite with inverse polymer proportions 
was over three times higher-12.0 MPa. On the other hand, from the strengthening point of view, the addition of straw in the case of samples with the same or preponderant content of EVA copolymer with respect to rubber content was proved to be unfavorable. Embedding $10 \mathrm{phr}$ of straw into the NR/EVA $30 / 70$ composite reduced the TS value by 32\%. The addition of straw component to 20 and $30 \mathrm{phr}$ reduced TS by as much as about $50 \%$ compared to the unfilled system (Figure 1 ). However, for samples NR/EVA 40/60 and NR/EVA 50/50, the negative effect of the biofiller was already much smaller, ranging from 16 to $32 \%$ (Table 1 and Figure 1). Composites containing more NR had initially less strength, but the addition of straw led to the most beneficial when compared to the corresponding straw-free blends. Sample NR/EVA 70/30, which had the lowest TS value without filler, after the addition of 20 and 30 phr straw was already as strong as samples containing more EVA with the same degree of filling. The large differences in the strength of unfilled composites substantially decreased as a result of the addition of almost the same values around $6 \mathrm{MPa}$ (see Table 1 and Figure 1).

Table 2. The mechanical properties of blends before and after the aging process.

\begin{tabular}{|c|c|c|c|c|c|}
\hline \multirow{2}{*}{ Sample } & \multirow{2}{*}{ Content of Filler [phr] } & \multicolumn{2}{|c|}{ Before Aging } & \multicolumn{2}{|c|}{ After Aging } \\
\hline & & TS [MPa] & $\mathrm{Eb}[\%]$ & TS [MPa] & $\mathrm{Eb}[\%]$ \\
\hline \multirow{4}{*}{ NR/EVA 70/30 } & 0 & 3.5 & 843 & 1.7 & 510 \\
\hline & 10 & 4.9 & 825 & 2.5 & 573 \\
\hline & 20 & 5.9 & 712 & 3.1 & 524 \\
\hline & 30 & 5.8 & 614 & 2.6 & 490 \\
\hline \multirow{4}{*}{ NR/EVA $60 / 40$} & 0 & 6.3 & 833 & 3.6 & 630 \\
\hline & 10 & 5.8 & 704 & 3.5 & 583 \\
\hline & 20 & 5.5 & 552 & 3.7 & 452 \\
\hline & 30 & 6.1 & 525 & 3.0 & 368 \\
\hline \multirow{4}{*}{ NR/EVA 50/50 } & 0 & 7.4 & 795 & 5.2 & 647 \\
\hline & 10 & 5.8 & 638 & 4.1 & 473 \\
\hline & 20 & 5.0 & 481 & 3.8 & 412 \\
\hline & 30 & 6.4 & 438 & 4.1 & 300 \\
\hline \multirow{4}{*}{ NR/EVA 40/60 } & 0 & 8.5 & 762 & 7.1 & 678 \\
\hline & 10 & 7.1 & 621 & 6.2 & 636 \\
\hline & 20 & 5.7 & 463 & 4.6 & 352 \\
\hline & 30 & 6.3 & 426 & 4.6 & 307 \\
\hline \multirow{4}{*}{ NR/EVA 30/70 } & 0 & 12.0 & 756 & 10.0 & 748 \\
\hline & 10 & 8.1 & 589 & 6.5 & 549 \\
\hline & 20 & 6.2 & 460 & 4.6 & 416 \\
\hline & 30 & 6.3 & 432 & 4.6 & 354 \\
\hline
\end{tabular}

The same type of straw of similar shape, size and susceptibility to agglomeration was used in all filled blends. One of the parameters affecting the mechanical strength of composites is the filler-polymer interactions. The tensile strength results indirectly prove that at higher straw content, their dispersion in the polymeric matrix is optimal and the biofiller makes eventually a reinforcing structure into the studied ternary blends. Accordingly, the filler-polymer interactions are favorable enough to avoid straw aggregation/agglomeration into larger particles and, at the same time, the strength of the filler-filler interactions were enough to create percolation pathways that may carry any potential applied stress.

The highest elongation at break (ca. 800-900\%) was achieved by composites containing a larger amount of NR (Table 2). A characteristic feature of natural rubber obtained even after crosslinking is its very high $\mathrm{Eb}$ values. The use of straw reduced the flexibility and, consequently, Eb values for all the prepared biocomposites as its volume/weight content raised. This effect was observed for almost all filled systems. Under the influence of external stresses, elastomer chains may easily undergo huge deformations as a result of large degree of freedom available for the macromolecular segments. 
The presence of biofiller particles diminishes the free volume associated to elastomeric component, reducing its ability to lightly change its dimensions on molecular scale.

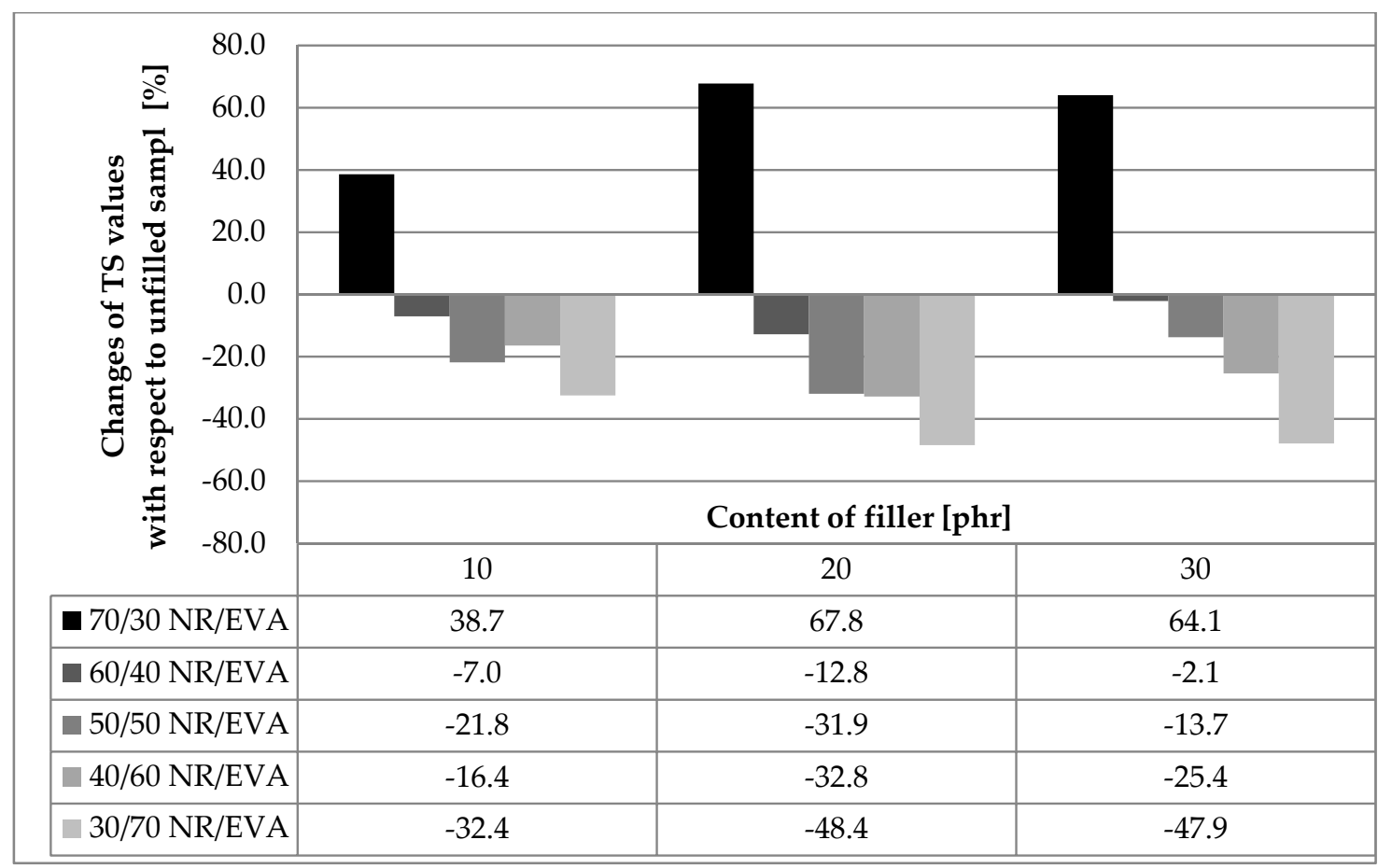

Figure 1. The percentage change in tensile strength for straw-based blend compared to unfilled systems.

\subsection{The Thermo-Oxidative Aging Process}

The resistance of the prepared biocomposites to thermo-oxidative aging has been determined based on changes in their mechanical properties. Analyzing the results of tensile strength and relative elongation of blends before and after aging (Table 2), it was noted that at the highest EVA content of the tricomponent systems, the TS values decreased by $20-25 \%$ almost regardless of the amount of straw. The tensile strength of the samples with the highest NR content was reduced by half. As expected, increasing the percentage of EVA in the blends enhanced the resistance to thermo-oxidative aging of the entire systems. The beneficial effect of increased EVA content in composites to the aging resistance of systems was also visible when comparing Eb values. The elongation at break of NR/EVA 30/70 samples was reduced by $1-18 \%$ and by $20-40 \%$ for the systems with the reverse proportion.

In order to more easily determine changes in the deformation energy of composites after simulated thermo-oxidative aging processes, the aging coefficient $\mathrm{K}$ was calculated. It is a numerical measure of the composite's resistance to aging. The closer its value to 1 , the smaller the changes in the tested properties before and after aging. The lowest aging rate was observed for composites containing 70 and 60 phr of EVA copolymer, filled with 10 phr of straw (Figure 2). For example, the beneficial effect (10 phr) of straw was particularly evident in the 40/60 NR/EVA composite, where the K value increased by 0.20 compared to the $\mathrm{K}$ value for NR/EVA 30/70 composites. In the case of blends with a natural rubber/EVA copolymer ratio of 70/30 and 60/40, the addition of straw to 10 and 20 phr had a positive effect on the composite's resistance to thermo-oxidative aging. The increase of the K coefficient caused by the addition of straw could be due to the presence of lignin. Its structure includes polyphenols, which are well-known as natural antioxidants. More specifically, they are primary antioxidants that provide an electron or hydrogen atom to the reactive polymer radicals [26]. So, the final products can be either non-radical or radical species, the latter being stable radicals, which may interrupt degradation of polymeric components via free-radical mechanism during aging process. Another reason for slowing down the aging process could be the increased barrier of the material. The rate of 
deterioration of polymer properties as a result of exposure to temperature, light and other external conditions is closely dependent on the rate of oxygen diffusion into the material. With a proper fiber dispersion, oxygen penetration through the interface between the NR/EVA structure and crystalline cellulose regions is hindered, leading to the formation of a fewer free radicals. Nevertheless, it should be considered that, apart from polyphenols, the biofiller contains a lot of aging-sensitive compounds, such as cellulose. Too much filler in the composite led to the deterioration of the composites' aging resistance. The composites with the addition of straw showed lower thermal stability (Part 1) because an amount of the NR/EVA components was replaced by straw with a relatively low decomposition temperature. In this case, the overall thermal energy needed to induce chemical transformations was much smaller, so the initiation of thermo-oxidation occurred easier and faster.

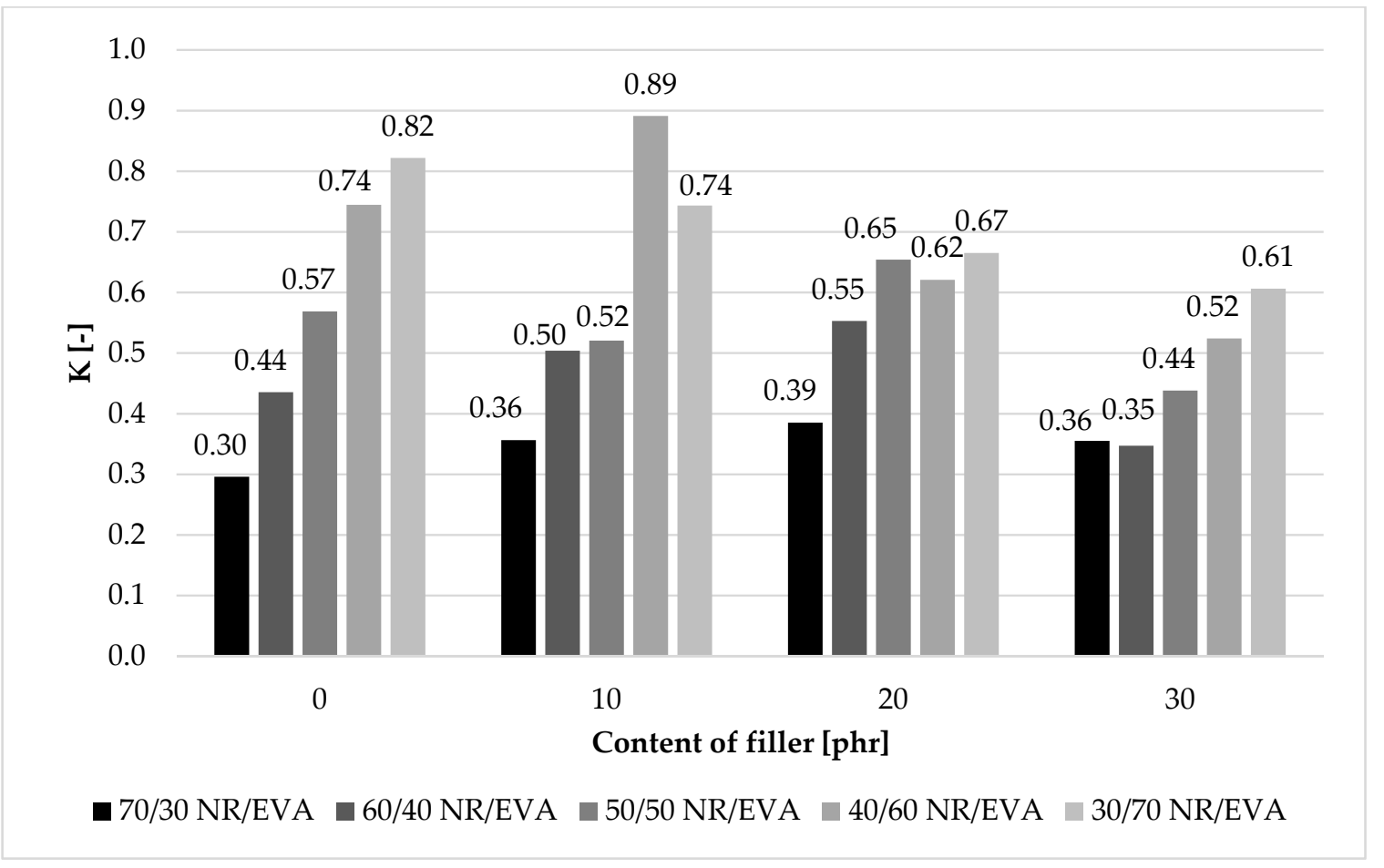

Figure 2. The thermo-oxidative aging factor of blend natural rubber/ethylene-vinyl acetate copolymer blends.

\subsection{Damping Properties}

The relative damping of filler-free composites was around 30-35\% (Figure 3). For straw-filled

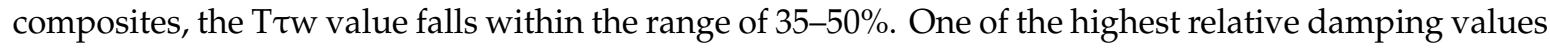
was obtained for composites NR/EVA 40/60 and 30/70 with the addition of 20 phr straw. Equally, high damping was demonstrated by sample NR/EVA/straw 60/40/30. Considering the results for all blends, the addition of straw increased the relative damping value, most for $20 \mathrm{phr}$ content. In composites without the addition of straw, the higher content of the EVA copolymer had a beneficial effect on the value of damping coefficient. NR/EVA 40/60 composites were characterized by the highest vibration absorption capacity. For the filler-based samples, the effect of EVA did not obey a monotone tendency. Thus, higher values of dumping coefficient were observed for both the ratio of NR to EVA 40/60, 30/70 and 60/40. 
$60.0 \%$

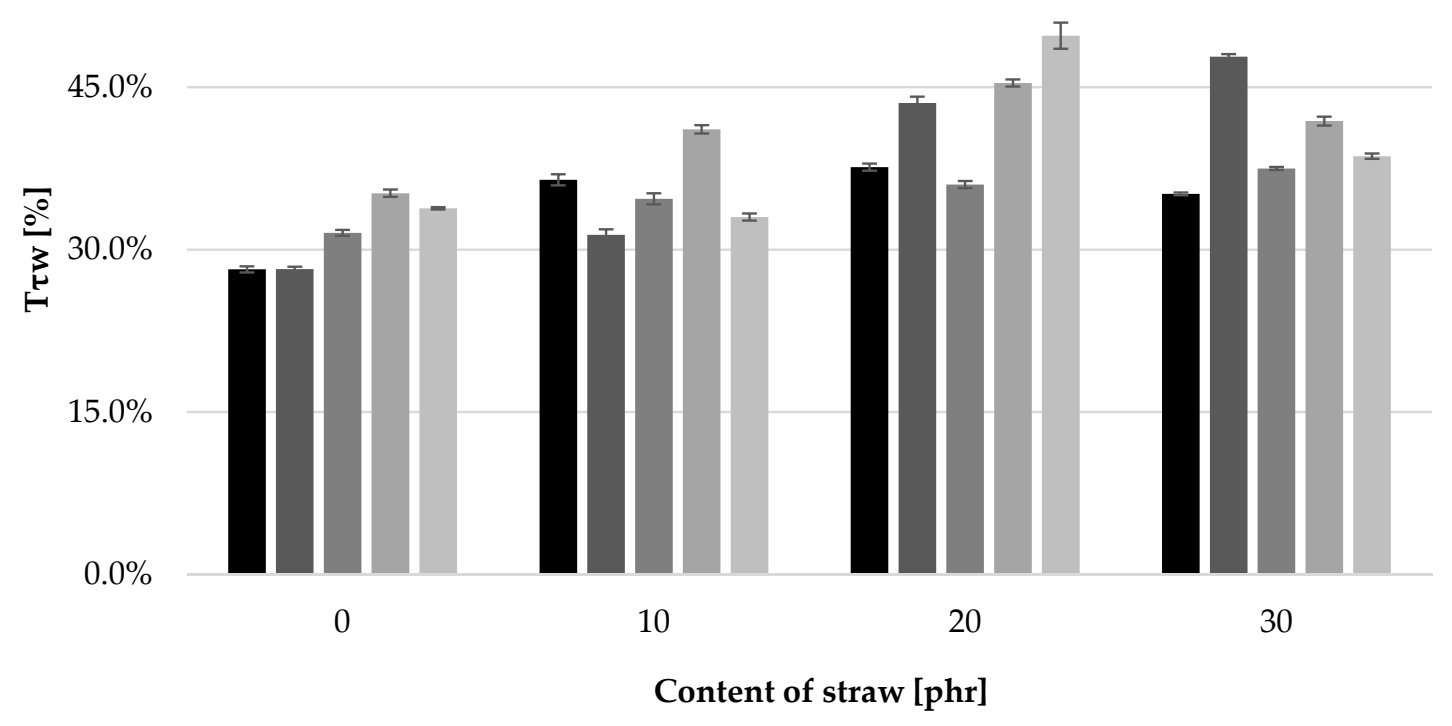

70/30 NR/EVA $\square$ 60/40 NR/EVA $\square$ 50/50 NR/EVA $\square$ 40/60 NR/EVA $\square$ 30/70 NR/EVA

Figure 3. The relative damping factor of unfilled and filled with straw natural rubber/ ethylene-vinyl acetate copolymer (NR/EVA) blends.

According to the elastic solid theory, under the influence of external forces, material particles move from the original state of equilibrium to another. This movement is counteracted by internal forces and if they are large, the displacement is small. After removing the external forces, internal forces tend to restore, without heat loss, the particles to their original position and the deformation is is pure. The main feature of elastic materials is the large deformability (shortening angle, deflection) in the direction of the force. In this way they accumulate potential energy, absorb vibrations and mitigate impacts. In addition, elastic elements into a viscous matrix not only receive but also dissipate energy. Rubber parts with sufficiently high damping ability can work in various drives and even support steel structures and systems. Compounds filled with straw, especially with $20 \mathrm{phr}$ and/or containing more EVA, would work best as vibration-absorbing and impact-absorbing materials. Such materials would be able to accumulate a lot of potential energy without any damages on them.

\subsection{Hardness}

The hardness of all samples was in the range of 37-78 Shore A degrees (Figure 4). With the increase in EVA content, its value also increased, almost in a linear way. For samples containing $70 \mathrm{phr}$ of NR and $30 \mathrm{phr}$ of EVA, the hardness was about 40. In the case of samples with the inverse proportion, the hardness increased almost twice as a result of the higher content of the crystalline phase. The addition of straw also increased the hardness by several units for each of the tested blends. The reason for the higher hardness, in this case, was also the increase in the content of the crystalline phase because the cellulose that builds the straw fibers has a high degree of order.

\subsection{Tear Strength}

The study showed that there was a close relationship between EVA content and blend tear resistance (Figure 5). The higher the copolymer content, the greater the force needed to break the sample. The $\mathrm{F}_{\text {mit }}$ value of NR/EVA 30/70 samples was about 4 times higher than the NR/EVA 70/30 blend, almost regardless of the presence of straw. Samples containing more rubber had a tear strength of 5-7 N/mm, and with increasing EVA content, the strength increased up to $20 \mathrm{~N} / \mathrm{mm}$. The intermolecular 
interactions associated to the copolymer component (cohesive forces), as a result of its crystalline/glassy state at room temperature, are substantially greater than those within natural rubber microdomains and represents an appreciable energy barrier for incision propagation. The addition of straw also increased the tear resistance of composites. On average, the highest values were obtained for the addition of 20 phr of straw. In such a proportion, the fibers create a tear-limiting barrier that, when crossed, requires more force to be applied.

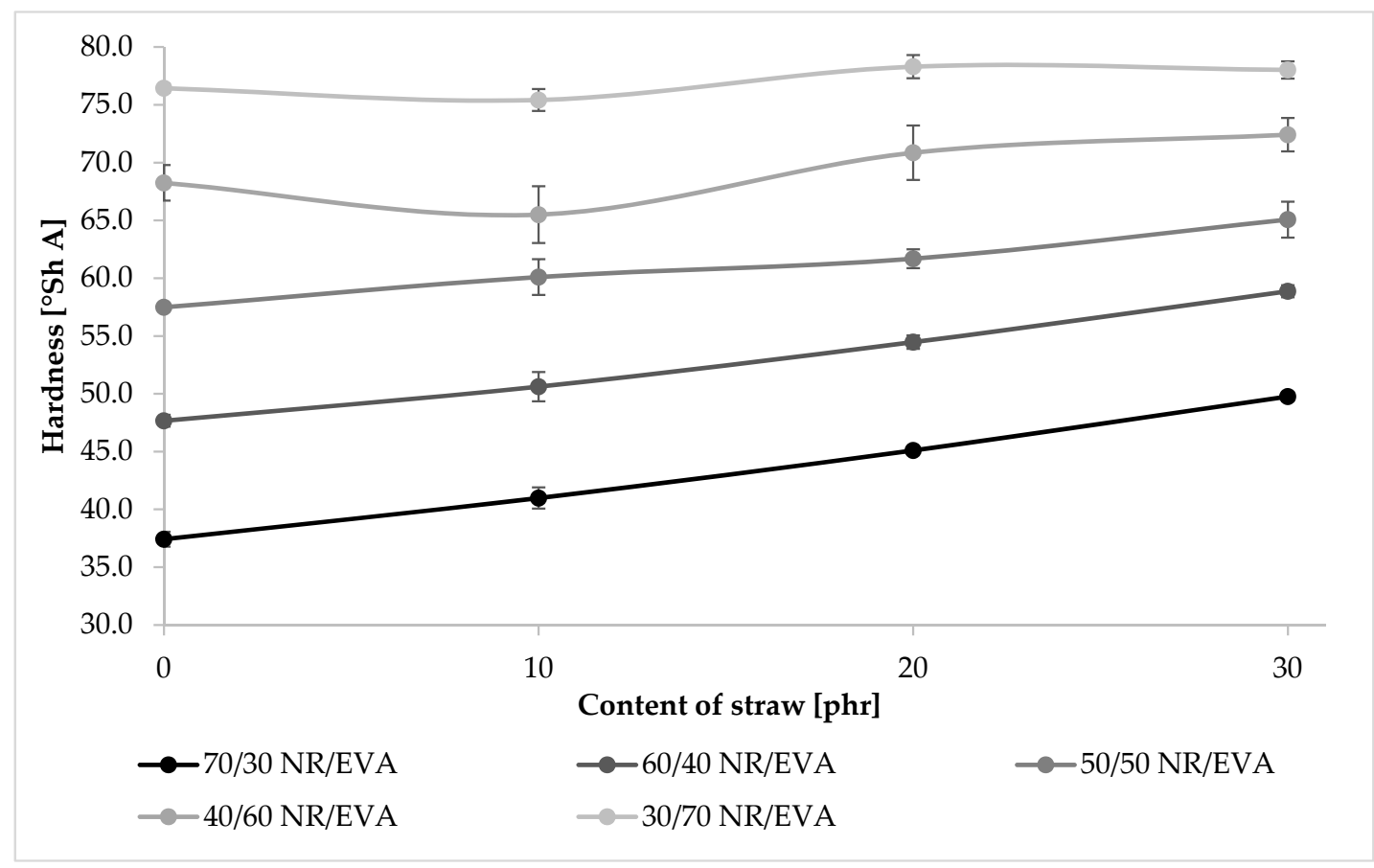

Figure 4. The hardness values of biocomposites.

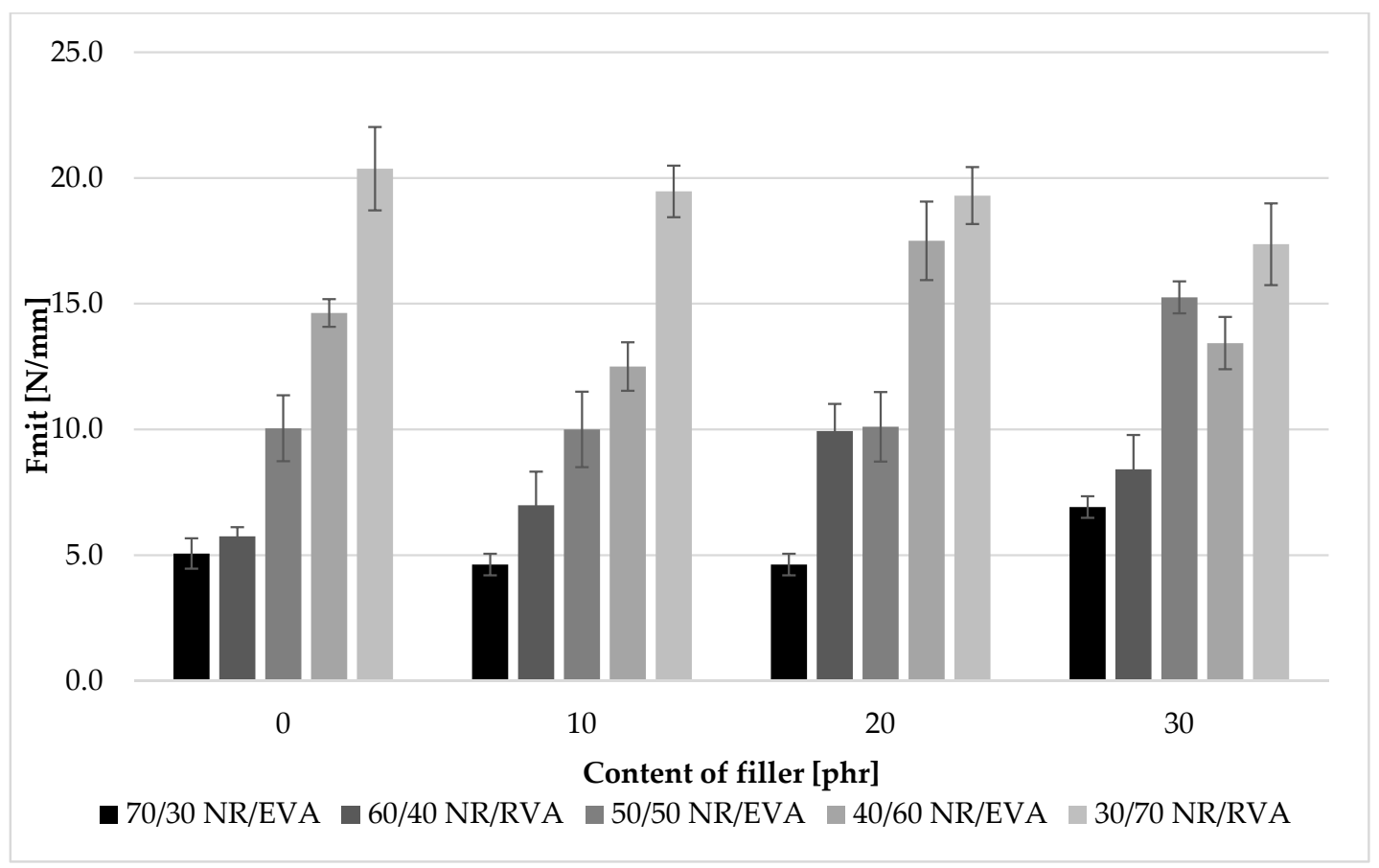

Figure 5. The average strength needed to tear the sample (Fmit) of NR/EVA or NR/EVA/ straw composites. 


\subsection{Flammability}

Measurement of the burning time of samples in the air allowed to assess the effect of the amount of polymers (NR, EVA) and straw on the flammability of composites (Table 3). As expected, EVA slowed the burning of composites, but the effect was visible only for the ternary blends with 20 and $30 \mathrm{phr}$ of straw. The combustion time of NR/EVA 30/70 samples filled with 20 and 30 parts by weight of straw was longer by over $1.5 \mathrm{~min}$ than of NR/EVA 70/30 samples with the same degree of filling. A relatively surprising result was the extension of the burning time of the samples due to straw filling. Although the straw itself burned quickly and with a large flame, its addition to the polymer composite significantly slowed down the burning of the entire system. For example, embedding an amount of $10 \mathrm{phr}$ of straw extended the burning time of the NR/EVA 70/30 sample from 219 to $351 \mathrm{~s}(60 \%)$ and for NR/EVA 40/60 from 215 to $301 \mathrm{~s}(40 \%)$. Increasing the amount of straw extended the burning time by several dozen seconds for samples NR/EVA 40/60 and 30/70. Sample NR/EVA/straw 30/70/30 burned the longest, almost $7.5 \mathrm{~min}$, while the shortest—unfilled composite NR/EVA 50/50, $3.5 \mathrm{~min}$.

Table 3. The flammability of composites.

\begin{tabular}{ccccc}
\hline \multicolumn{5}{c}{ Total Burning Time [s] } \\
\hline \multirow{2}{*}{ NR/EVA } & \multicolumn{4}{c}{ Content of Filler [phr] } \\
\cline { 2 - 5 } & $\mathbf{0}$ & $\mathbf{1 0}$ & $\mathbf{2 0}$ & $\mathbf{3 0}$ \\
\hline $\mathbf{7 0 / 3 0}$ & 219 & 351 & 317 & 327 \\
$\mathbf{6 0 / 4 0}$ & 227 & 346 & 327 & 303 \\
$\mathbf{5 0 / 5 0}$ & 209 & 335 & 350 & 344 \\
$\mathbf{4 0 / 6 0}$ & 215 & 301 & 350 & 382 \\
$\mathbf{3 0 / 7 0}$ & 254 & 310 & 411 & 445 \\
\hline
\end{tabular}

During the tests, differences in the manner of burning individual materials were also observed. First of all, the unfilled blend samples dripped, and the flame spread with the flowing drops. In addition, the flow of melted polymer droplets was higher at higher ethylene-vinyl acetate copolymer contents in the blend. This is due to the fact that EVA has a relatively low melting point and lower viscosity than NR, which makes it quicker to flow. In the event of a fire, the dripping phenomenon is extremely dangerous because the flowing drops transfer the flame to nearby elements and the area of the fire increases. More favorable results in terms of flame retardancy were obtained for straw-filled composites, especially for 20 and $30 \mathrm{phr}$ of filling. These samples did not drip, and the flame that covered them at the same stages of smoking was clearly smaller. The method of smoking and the difference in flame size between samples without and with straw addition observed 30 and $60 \mathrm{~s}$ after the ignition are shown in Figure 6.

The reason for slowing down the composite burning was probably a decrease in air permeability and thus limited oxygen diffusion into the burning sample. The increase in barrier properties of composites with the addition of straw has been proven in air permeability studies. In addition, the spread of liquid polymer combustion products has been eliminated. The higher the straw content in the composite, the lower the gas permeation coefficient and the lower the permeability were observed. Straw fibers formed areas in the polymer matrix that are difficult to avoid by gas molecules. For this reason, oxygen diffusion into the polymer blends was slower. Smoking strictly depends on the amount of oxygen available, therefore limiting its amount has slowed down the combustion process. In addition, straw increased the viscosity of the material, which significantly reduced the spreading of the liquid material and affected the burning time. It is also very possible that the liquid EVA copolymer, instead of flowing down the sample, has been absorbed by straw fibers.

The study showed that among composites filled with $10 \mathrm{phr}$ lignocellulosic material, samples with a higher content of NR were less flammable. In contrast, blends containing 20 and $30 \mathrm{phr}$ of biofiller burned longer if they contained more EVA than NR. In terms of burning retardation, the most 
advantageous was the use of 30/70, 40/60 and 50/50 NR/EVA composites filled with 20 and 30 parts by weight of a straw. Potentially, they could be used as LSZH (Low Smoke, Zero Halogen) materials due to the lack of halogens and the significant slowdown in smoking compared to pure NR. Typically, such materials are filled with inorganic additives, limiting the amount of diffusing oxygen, increasing thermal capacity and affecting the rheology of the polymer. These types of fillers undergo endothermic decomposition, absorb heat from the polymer and produce inert gases that reduce the concentration of free radicals conditioning the maintenance of the combustion reaction [27]. Although straw is an organic material, some of these effects most likely occur when used in composites.

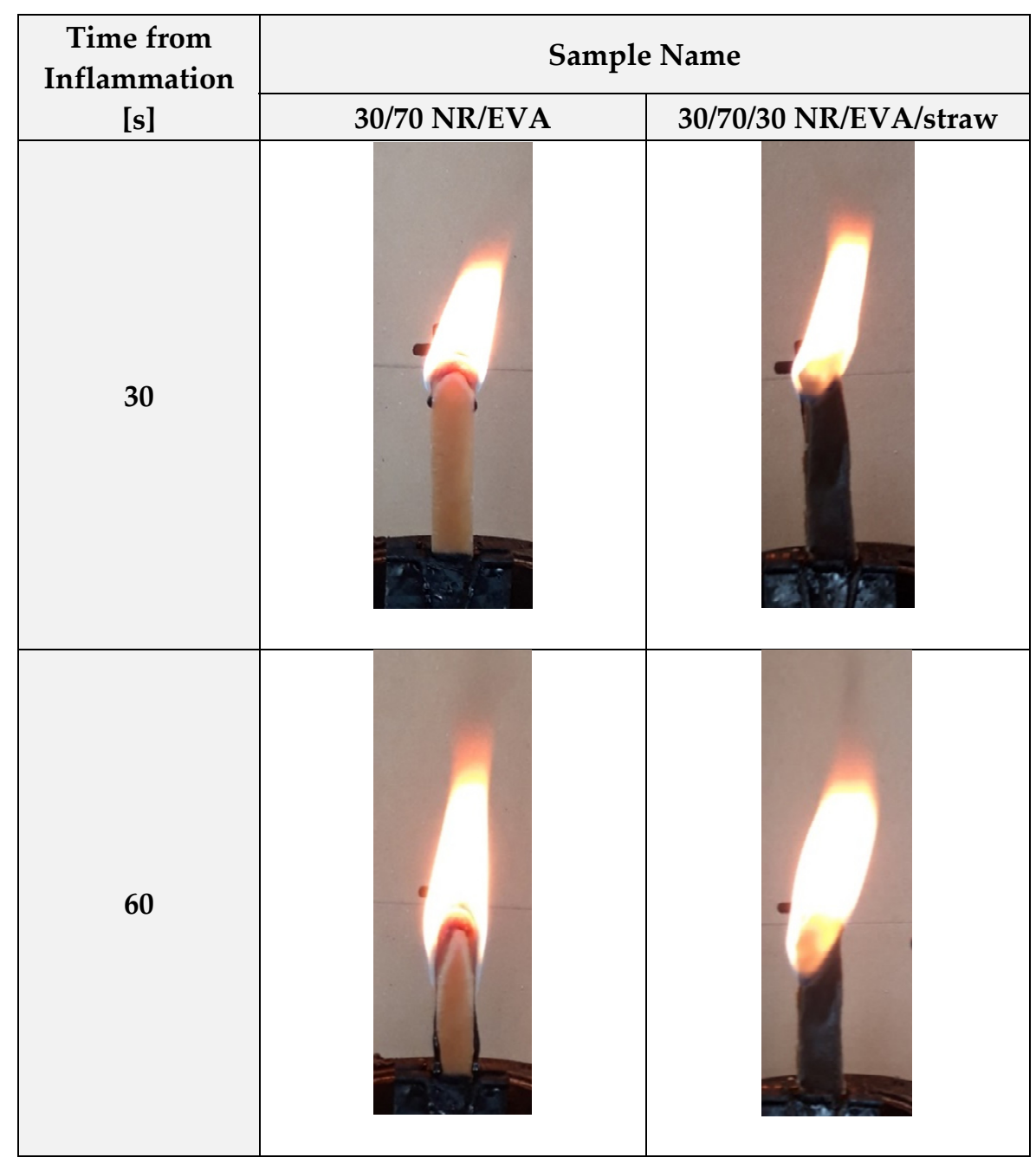

Figure 6. The comparison of sample behavior during combustion for 30/70 NR/EVA (unfilled and filled with 30 phr straw).

\subsection{Barrier Properties}

The barrier properties of the obtained blends were significantly different depending on the ratio of the polymers used to form the polymer matrix as well as the amount of bio-filler used (Table 4). To exemplify, the gas transmission rate (GTR) for the material made of NR/EVA/biofiller 70/30/10 reached the highest value of $2.04 \cdot 10^{-8} \mathrm{~mol} /\left(\mathrm{m}^{2} \cdot \mathrm{s} \cdot \mathrm{Pa}\right)$. The study carried out for composites with a lower natural rubber content revealed a huge impact of EVA fraction on the gas transmission rate of blends. Even a small change in the ratio NR/EVA from 70/30 to 60/40 led to reducing the gas transmission rate by up to $80 \%$. Further increasing the amount of EVA in the blend resulted in a decrease in sample permeability, but the differences were less significant. 
Table 4. The barrier properties of polymer blends based on natural rubber and ethylene-vinyl acetate copolymer filled with straw.

\begin{tabular}{|c|c|c|c|c|}
\hline \multicolumn{5}{|c|}{$\mathrm{P} \cdot 10^{11}[\mathrm{~mol} /(\mathrm{m} \cdot \mathrm{s} \cdot \mathrm{Pa})]$} \\
\hline \multirow{2}{*}{ NR/EVA } & \multicolumn{4}{|c|}{ Content of Filler [phr] } \\
\hline & 0 & 10 & 20 & 30 \\
\hline $70 / 30$ & 2.34 & 2.86 & 2.32 & 2.04 \\
\hline $60 / 40$ & 0.64 & 0.50 & 0.47 & 0.44 \\
\hline $50 / 50$ & 0.53 & 0.36 & 0.37 & 0.39 \\
\hline $40 / 60$ & 0.46 & 0.41 & 0.31 & 0.25 \\
\hline $30 / 70$ & 0.25 & 0.24 & 0.22 & 0.24 \\
\hline \multicolumn{5}{|c|}{$\mathrm{GTR} \cdot 10^{8}\left[\mathrm{~mol} /\left(\mathrm{m}^{2} \cdot \mathrm{s} \cdot \mathrm{Pa}\right)\right]$} \\
\hline \multirow{2}{*}{ NR/EVA } & \multicolumn{4}{|c|}{ Content of Filler [phr] } \\
\hline & 0 & 10 & 20 & 30 \\
\hline $70 / 30$ & 1.91 & 2.04 & 1.68 & 1.60 \\
\hline $60 / 40$ & 0.44 & 0.42 & 0.36 & 0.35 \\
\hline $50 / 50$ & 0.41 & 0.31 & 0.30 & 0.28 \\
\hline $40 / 60$ & 0.32 & 0.31 & 0.23 & 0.21 \\
\hline $30 / 70$ & 0.21 & 0.20 & 0.18 & 0.18 \\
\hline
\end{tabular}

The addition the straw also exhibited a positive effect on the barrier properties of composites. The changes caused by its addition were not as large as when increasing the EVA content, but nonetheless observable. In almost all cases, the transmission rate gradually decreased as the straw content increased. The greatest effect of the filler on the rate of air permeation through the composite was observed with the addition of $30 \mathrm{phr}$ for composite NR/EVA 40/60. The GTR value for this blend decreased from $3.25 \times 10^{-9}$ to $2.09 \cdot \times 10^{-9} \mathrm{~mol} /\left(\mathrm{m}^{2} \cdot \mathrm{s} \cdot \mathrm{Pa}\right)$, which is a difference of $34 \%$ compared to the reference system. The improved barrier properties of the blend resulted from the greater crystallinity of the EVA copolymer (in conjunction with the glassy state of copolymer at room temperature), hence from the greater orderliness and stability of the structure limiting the gas penetration of the material. The surprising result is the significant difference between the samples NR/EVA 70/30 and NR/EVA $60 / 40$ and relatively small between samples containing more and more copolymer. This effect is most likely related to the percolation theory: the probability that the gas will find its way from one side of the sample to the other depends on the number of paths available to its molecules.

Analyzing the results of air permeability through composites $(\mathrm{P})$ considering the thickness of the sample, it could be seen that the addition of straw reduced the permeability, to the greatest extent for the sample NR/EVA 40/60. The value of $\mathrm{P}$ as a result of adding 30 parts by weight decreased almost by half from $4.64 \times 10^{-12}$ to $2.49 \times 10^{-12} \mathrm{~mol} \cdot \mathrm{m} /\left(\mathrm{m}^{2} \cdot \mathrm{s} \cdot \mathrm{Pa}\right)$. The filler in this amount also had a large impact on the permeability of samples with a $60 / 40$ and 50/50 rubber to copolymer ratio-a reduction of about $30 \%$. In the NR/EVA 70/30 sample, the reduction was smaller-13\%, and in the NR/EVA 30/70 composite-the smallest (ca. 4-12\%). In the filled composites, gas molecules must travel a longer distance in the polymer matrix. The dispersed straw fibers create further barriers that the gas must bypass, which limits its diffusion. This effect can be compared with a maze, the narrower the paths and turns, the more difficult it is to get to the other side. The more straw fibers, the more barriers and the more complicated the maze. This was in line with the results obtained, which showed that a larger amount of straw resulted in the greater barrier. High barrier, so the smallest possible gas permeation coefficient for a given material, is crucial for most applications of polymeric materials. This is one of the main properties that determine such wide use of plastics, e.g., in the packaging industry and construction. Therefore, reducing the rate of gas permeation through the addition of straw and copolymer is very desirable.

The paper presents research on thermoplastic elastomers in the form of blends made of ethylene-vinyl acetate and natural rubber with different mass fractions of these polymers. In addition, 
natural fibers (ground cereal straw) were introduced into these systems, which allowed to increase the share of raw materials of natural origin in the composite, bring material benefits, and propose the possibility of their utilization. When introducing new technological solutions, it is extremely important to recognize and characterize newly created materials.

To sum up the whole work (Part 1 and 2), it should be emphasized that newly formed composites are combining the advantages of natural rubber and EVA copolymer and partly eliminating their disadvantages (e.g., high aging susceptibility of NR). Produced NR/EVA blends with a co-continuous structure were characterized by high flexibility while maintaining strength at the appropriate level. The homogeneous dispersion of the straw filler has contributed to a positive effect on a number of functional properties such as barrier, flammability, damping and mechanical strength. The ecological aspect related to the use of natural, renewable, agricultural waste was also significant. In addition, due to the appropriate processing conditions, cross-linking of composites has been eliminated, which facilitates material recycling and its re-use. From the point of view of material engineering, the innovative NR/EVA/straw blends present high application potential, create the possibility of using straw surpluses and fit into the trend of sustainable development principles.

\section{Conclusions}

The proposed blends are characterized by interesting and diverse properties depending on the material composition. Blends containing a predominance of ethylene-vinyl acetate copolymer were characterized by reduced elongation at break, while increased tensile strength. It is noteworthy that straw has reduced tensile strength in these systems. In turn, in the case of the larger mass friction of natural rubber in blends, the straw was able to create a more extensive secondary structure, with a significant strengthening character. The biocomposites produced were characterized by varied resistance to thermo-oxidative aging. The increased EVA content in the blend allowed to obtain composites with higher resistance to degradation under the influence of increased temperature. However, the impact of straw depended on its quantity and type of blend. The hardness at the highest EVA content almost doubled, and the addition of straw also increased it. Tests on damping properties have shown that composites containing more EVA and filler can find potential applications in finished products that absorb vibrations and mitigate impacts. The positive effect of the combination of natural rubber with the ethylene-vinyl acetate copolymer as well as the straw was also observed on the basis of tear strength results. The addition of ethylene-vinyl acetate copolymer to natural rubber also had a huge impact on the barrier properties of the material. Furthermore, straw fibers have also increased the barrier properties of composites. The fibrous nature of the filler used has resulted in a structure that significantly extends the gas diffusion path through the sample. The flammability test of composites also brought promising results. Among samples filled with $10 \mathrm{phr}$ straw, those with a higher NR content were less flammable. The straw contained in the composite contributed to the absorption of liquid decomposition products and prevented the spread of flame, which is an extremely advantageous aspect from the point of view of polymer materials exposed to fire.

Author Contributions: Conceptualization, J.M., M.M., K.S.; methodology J.M.; formal analysis, K.S.; investigation, J.M and M.M.; resources, M.M.; data curation, J.M and M.M.; writing-original draft preparation, M.M and J.M.; writing-review and editing, J.M and M.M.; supervision, K.S. All authors have read and agreed to the published version of the manuscript.

Funding: This work was supported by the National Science Centre, Poland (PRELUDIUM no. 2018/31/N/ST8/ 00802).

Conflicts of Interest: The authors declare no conflict of interest.

\section{References}

1. McMullin, E. Biodegradable Thermoplastic Elastomers and Smart Composites. Ph.D. Thesis, Syracuse University, Syracuse, NY, USA, 2016. 
2. Krasnov, K.V.; Chalaya, N.M.; Osipchik, V.S. The modification of blend composites based on thermoplastic elastomers. Int. Polym. Sci. Technol. 2016, 43, 43-46. [CrossRef]

3. Rzymski, W.M.; Radusch, H.J. Nowe elastomery termoplastyczne. Polimery 2005, 50, 249-254. [CrossRef]

4. Katbab, A.A.; Nazockdast, H.; Bazgir, S. Carbon black-reinforced dynamically cured EPDM/PP thermoplastic elastomers. I. Morphology, rheology, and dynamic mechanical properties. J. Appl. Polym. Sci. 2000, 75, 1127-1137. [CrossRef]

5. George, S.; Neelakantan, N.R.; Varughese, K.T.; Thomas, S. Dynamic mechanical properties of isotactic polypropylene/nitrile rubber blends: Effects of blend ratio, reactive compatibilization, and dynamic vulcanization. J. Polym. Sci. Part B Polym. Phys. 1997, 35, 2309-2327. [CrossRef]

6. Thamronglerdrit, T.; Magaraphan, R. Effect of blend composition of epoxidized natural rubber and fluoroplastic via dynamic vulcanization. In Proceedings of the Annual Technical Conference-ANTEC, Orlando, FL, USA, 2-4 April 2012; Volume 3, pp. 2303-2306.

7. Mollik, S.; Tariq, I.; Hasan, M.H. Structural Applications and Emerging Trends of Nano- and Biocomposites: A Review. Adv. Mater. Res. 2015, 1115, 345-348. [CrossRef]

8. Cyga, R.; Czaja, K. Kompozyty polimerowe z napełniaczem roślinnym. Przemyst Chemiczny 2008, 87, $932-936$.

9. Akampumuza, O.; Wambua, P.M.; Ahmed, A.; Li, W.; Qin, X.H. Review of the applications of biocomposites in the automotive industry. Polym. Compos. 2017, 38, 2553-2569. [CrossRef]

10. Ouyang, C.; Wang, Y.; Zhao, N.; Liu, X.; Li, S.; Zhang, Z. Preparation of poly(lactic acid) and modified starch composites. Polym. Bull. 2012, 68, 2009-2019. [CrossRef]

11. Gutiérrez, T.J.; Alvarez, V.A. Cellulosic materials as natural fillers in starch-containing matrix-based films: A review. Polym. Bull. 2017, 74, 2401-2430. [CrossRef]

12. Ismail, H.; Munusamy, Y.; Jaafar, M.; Ratnam, C.T. Preparation and characterization of ethylene vinyl acetate (EVA)/natural rubber (SMR L)/organoclay nanocomposites: Effect of blending sequences and organoclay loading. Polym.-Plast. Technol. Eng. 2008, 47, 752-761. [CrossRef]

13. Hashim, F.; Ismail, H.; Rusli, A. Comparison of properties of ethylene vinyl acetate/natural rubber/mengkuang leaf fibre (EVA/NR/MLF) and ethylene vinyl acetate/epoxidized natural rubber/mengkuang leaf fibre (EVA/ENR-50/MLF) thermoplastic elastomer composites. Polym. Test. 2017, 61, 1-7. [CrossRef]

14. Li, X.; Tabil, L.G.; Panigrahi, S. Chemical treatments of natural fiber for use in natural fiber-reinforced composites: A review. J. Polym. Environ. 2007, 15, 25-33. [CrossRef]

15. Sgriccia, N.; Hawley, M.C.; Misra, M. Characterization of natural fiber surfaces and natural fiber composites. Compos. Part A Appl. Sci. Manuf. 2008, 39, 1632-1637. [CrossRef]

16. Fuqua, M.A.; Huo, S.; Ulven, C.A. Natural Fiber Reinforced Composites. Polym. Rev. 2012, 52, 259-320. [CrossRef]

17. Al-Oqla, F.M.; Sapuan, S.M. Natural fiber reinforced polymer composites in industrial applications: Feasibility of date palm fibers for sustainable automotive industry. J. Clean. Prod. 2014, 66, 347-354. [CrossRef]

18. Madurwar, M.V.; Ralegaonkar, R.V.; Mandavgane, S.A. Application of agro-waste for sustainable construction materials: A review. Constr. Build. Mater. 2013, 38, 872-878. [CrossRef]

19. Masłowski, M.; Miedzianowska, J.; Strzelec, K. Natural rubber biocomposites containing corn, barley and wheat straw. Polym. Test. 2017, 63, 84-91. [CrossRef]

20. Masłowski, M.; Miedzianowska, J.; Strzelec, K. Cereal straw and their physical modifications with hydrophilic and hydrophobic silica-The influence of functional hybrid material on natural rubber biocomposites. Eur. Polym. J. 2019, 112, 176-185. [CrossRef]

21. Masłowski, M.; Miedzianowska, J.; Strzelec, K. Natural Rubber Composites Filled with Cereals Straw Modified with Acetic and Maleic Anhydride: Preparation and Properties. J. Polym. Environ. 2018, 26, 4141-4157. [CrossRef]

22. Miedzianowska, J.; Masłowski, M.; Strzelec, K. Thermoplastic elastomer biocomposites filled with cereal straw fibers obtained with different processing methods-preparation and properties. Polymers 2019, 11, 641. [CrossRef]

23. Maciejewska, M.; Sowinska, A.; Kucharsk, J. Organic zinc salts as pro-ecological activators for sulfur vulcanization of styrene-butadiene rubber. Polymers 2019, 11, 1723. [CrossRef] [PubMed]

24. Szadkowski, B.; Marzec, A.; Zaborski, M. Use of carbon black as a reinforcing nano-filler in conductivityreversible elastomer composites. Polym. Test. 2020, 81, 106222. [CrossRef] 
25. Strąkowska, A.; Kosmalska, A.; Masłowski, M.; Szmechtyk, T.; Strzelec, K.; Zaborski, M. POSS as promoters of self-healing process in silicone composites. Polym. Bull. 2019, 76, 3387-3402. [CrossRef]

26. Kirschweng, B.; Tátraaljai, D.; Földes, E.; Pukánszky, B. Natural antioxidants as stabilizers for polymers. Polym. Degrad. Stab. 2017, 145, 25-40. [CrossRef]

27. Hull, T.R.; Witkowski, A.; Hollingbery, L. Fire retardant action of mineral fillers. Polym. Degrad. Stab. 2011, 96, 1462-1469. [CrossRef] 